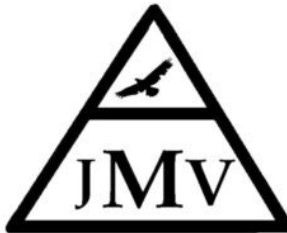

\section{Glossary and definitions of terms used in mechanical ventilation}

Robert L. Chatburn, MHHS, RRT-NPS, FAARC

DOI: https://doi.org/10.53097/JMV.10030

Cite: Chatburn RL. Glossary and definitions of terms used in mechanical ventilation. J Mech Vent 2021; 2(3):87-103.
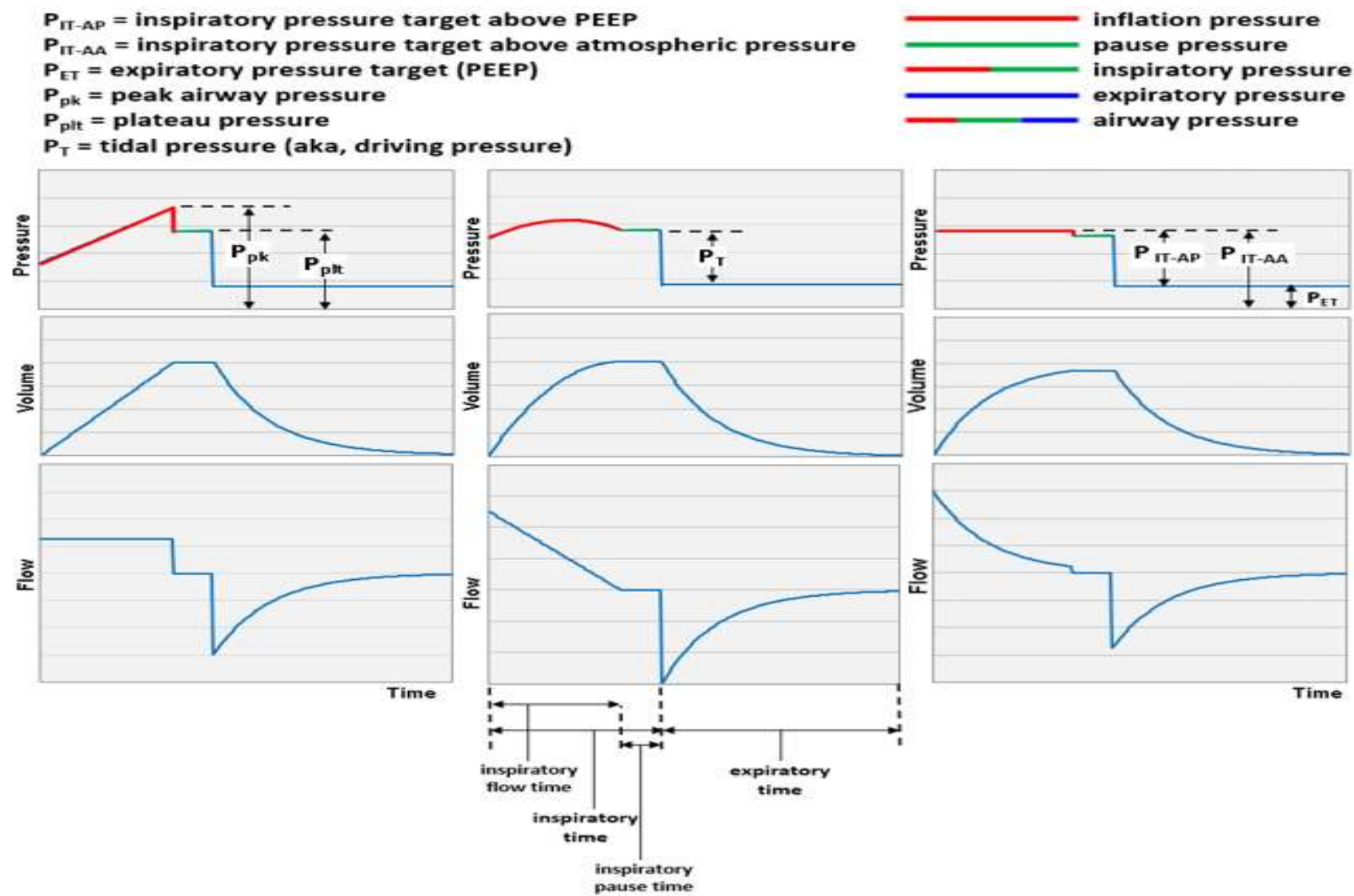

(Reproduced with permission by Mandu Press Ltd, copyright 2015)

Author

Adjunct Professor, Department of Medicine, Lerner College of Medicine of Case Western Reserve University.

Program Manager for Respiratory Care research and Director of the Simulation Fellowship at the Cleveland Clinic.

Corresponding author: Robert L Chatburn: chatbur@ccf.org

Conflict of interest/Disclosures: None Funding: None

Journal of Mechanical Ventilation 2021 Volume 2, Issue 3

This open-access article is distributed under the terms of the Creative Commons Attribution Non-Commercial License (CC BY-NC) (http://creativecommons.

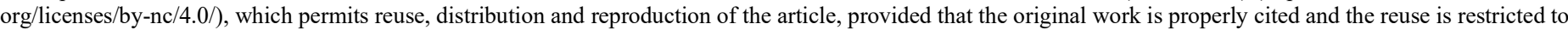
noncommercial purposes. For commercial reuse, contact: editor@journalmechanicalventilation.com 


\section{ACTIVE EXHALATION VALVE}

A mechanism for holding pressure in the breathing circuit by delivering the flow required to allow the patient breathe spontaneously. This feature is especially prominent in modes like Airway Pressure Release Ventilation that are intended to allow unrestricted spontaneous breathing during a prolonged mandatory (i.e., time triggered and time cycled) pressure controlled breath.

\section{ACTIVE VENTILATION}

Inspiratory muscles contribute to the generation of inspiratory flow. Active ventilation may be assisted by the ventilator (ie, the ventilator does some of the work of breathing) or unassisted. See ASSISTED BREATH

\section{ADAPTIVE TARGETING SCHEME}

A control system that allows the ventilator to automatically set some (or conceivably all) of the targets between breaths to achieve other preset targets. One common example is adaptive pressure targeting (e.g., Pressure Regulated Volume Control mode) where a static inspiratory pressure is targeted within a breath (i.e., pressure-controlled inspiration) but this target is automatically adjusted by the ventilator between breaths to achieve an operator set average tidal volume target (aka, volume-targeted pressure control).

\section{AIRWAY PRESSURE}

The pressure at the airway opening measured relative to atmospheric pressure during mechanical ventilation.

\section{AIRWAY PRESSURE RELEASE VENTILATION (APRV)}

A form of pressure control intermittent mandatory ventilation that is designed to allow unrestricted spontaneous breathing throughout the breath cycle. APRV is applied using I:E ratios much greater than 1:1 and usually relying on short expiratory times and gas trapping to maintain end expiratory lung volume rather than a preset PEEP. This is in contrast to Bilevel Positive Airway Pressure (BIPAP) which is also pressure control intermittent mandatory ventilation but with I:E ratios closer to $1: 1$, expiratory times that do not create significant gas tapping and preset PEEP levels above zero.

\section{ASYNCHRONY}

Asynchrony during mechanical ventilation is defined as the absence of one of the two reference waveforms generated by either the patient or the ventilator. See SYNCHRONY, DYSSYNCHRONY

\section{ASSISTED BREATH}

A breath during which all or part of inspiratory (or expiratory) flow is generated by the ventilator doing work on the patient. In simple terms, if the airway pressure rises above end expiratory pressure during inspiration, the inspiration is assisted (as in the Pressure Support mode). It is also possible to assist expiration by dropping airway pressure below end expiratory pressure (such as Automatic Tube Compensation). In contrast, spontaneous breaths during CPAP are unassisted because the ventilator attempts to maintain a constant airway pressure during inspiration.

\section{ATELECTRAUMA}

Ventilator induced lung injury caused by cyclic opening and closing of airway and pulmonary units due to insufficient PEEP and subsequent atelectasis on expiration. See VOLUTRAUMA

\section{AUTO-PEEP}

The positive difference between end-expiratory alveolar pressure (total or intrinsic PEEP) and the end-expiratory airway pressure (set or extrinsic PEEP).

When auto-PEEP exists, a positive pressure difference drives flow throughout exhalation until the subsequent breath interrupts deflation. Auto-PEEP is caused when expiratory time (either set by the patient's brain or a ventilator) is short relative to the expiratory time constant of the respiratory system (possibly including the expiratory resistance of the breathing circuit)."

\section{AUTOMATIC TUBE COMPENSATION}

A feature that allows the operator to enter the size of the patient's endotracheal tube and have the ventilator calculate the tube's resistance and then generate just enough pressure (in proportion to inspiratory or expiratory flow) to compensate for the added resistive load. See SERVO CONTROL 


\section{AUTO-TRIGGER}

A condition in which the ventilator repeatedly triggers itself because the sensitivity is set too high(sometimes called "autocycling"). The ventilator may auto-trigger due to a leak in the system dropping airway pressure below a pressure trigger threshold. When sensitivity is set too high, even the heartbeat can cause inadvertent triggering. Auto-triggering is a form of patient-ventilator asynchrony.

\section{BAROTRAUMA}

An obsolete term (from the 1970s) indicating ventilator induced lung damage from excessive inspiratory pressure. Current understanding is that the causative agent is not airway pressure but transalveolar or transpulmonary pressure difference. See VOLUTRAUMA

\section{BIOTRAUMA}

Ventilator induced lung damage caused by the release of proinflammatory cytokines and the recruitment of white cells, with lung inflammation occurring as a result applied stess and the resulting lung strain

\section{BIO-VARIABLE TARGETING SCHEME}

A control system that allows the ventilator to automatically set the inspiratory pressure or tidal volume randomly to mimic the variability observed during normal breathing. Currently this "biologically variable" targeting scheme is only available in one mode, Variable Pressure Support, on the Dräger V500 ventilator. The operator sets a target inspiratory pressure and a percent variability from $0 \%$ to $100 \%$. A setting $0 \%$ means the preset inspiratory pressure will be delivered for every breath. A $100 \%$ variability setting means that the actual inspiratory pressure varies randomly from PEEP/CPAP level to double the preset pressure support level.

\section{BLOWER}

A blower is a machine for generating relatively large flows of gas as the direct ventilator output with a relatively moderate increase of pressure (e.g., 2 psi). Blowers are used on home care and transport ventilators. See COMPRESSOR

\section{BREATH}

A positive change in airway flow (inspiration) paired with a negative change in airway flow (expiration), associated with ventilation of the lungs. This definition excludes flow changes caused by hiccups or cardiogenic oscillations. However, it allows the superimposition of, for example, a spontaneous breath on a mandatory breath or vice versa. The flows are paired by size, not necessarily by timing. For example, in Airway Pressure Release Ventilation there is a large mandatory inspiration (transition from low pressure to high pressure) possibly followed by a few small spontaneous inspirations and expirations, followed finally by a large expiration (transition from high pressure to low pressure). These comprise several small spontaneous breaths superimposed on one large mandatory breath. In contrast, during High Frequency Oscillatory Ventilation, small mandatory breaths are superimposed on larger spontaneous breaths.

\section{BREATH SEQUENCE}

A particular pattern of spontaneous and/or mandatory breaths.

The 3 possible breath sequences are: continuous mandatory ventilation, (CMV), intermittent mandatory ventilation (IMV), and continuous spontaneous ventilation (CSV).

\section{COMPLIANCE}

Defined as the ratio of the change in volume to the associated change in the pressure difference across the system. A mechanical property of a structure such as the respiratory system; a parameter of a lung model, or setting of a lung simulator. Compliance is the reciprocal of elastance.

\section{COMPRESSOR}

A compressor is a machine for moving a relatively low flow of gas to a storage container at a higher level of pressure (e.g, 20 psi). Compressors are generally found on intensive care ventilators whereas blowers are used on home care and transport ventilators. Compressors are typically larger and consume more electrical power than blowers, hence the use of the latter on small, portable devices. (see blower)

\section{CMV}

See CONTINUOUS MANDATORY VENTILAITON

\section{CONTINUOUS MANDATORY VENTILATION}

Commonly known as "Assist/Control"; CMV is a breath sequence for which spontaneous breaths are not permitted 
between mandatory breaths because every patient trigger signal in the trigger window produces a machine cycled inspiration (ie, a mandatory breath). Machine triggered mandatory breaths may be delivered at a preset rate.

Therefore, in contrast to IMV, the mandatory breath frequency may be higher than the set frequency but never below it. In some pressure controlled modes on ventilators with an active exhalation valve, spontaneous breaths may occur during mandatory breaths, but the defining characteristic of CMV is that spontaneous breaths are not permitted between mandatory breaths. See MANDATORY BREATH, INTERMITTENT MANDATORY VENTILATION, TRIGGER WINDOW

\section{CONTINUOUS SPONTANEOUS VENTILATION}

A breath sequence for which all breaths are spontaneous.

\section{CONTROL VARIABLE}

The variable (ie, pressure or volume in the equation of motion) that the ventilator uses as a feedback signal to manipulate inspiration. For simple set-point targeting, the control variable can be identified as follows: If the peak inspiratory pressure remains constant as the load experienced by the ventilator changes, then the control variable is pressure. If the peak pressure changes as the load changes but tidal volume remains constant, then the control variable is volume. Volume control implies flow control and vice versa, but it is possible to distinguish the two on the basis of which signal is used for feedback control. Some modes (eg, High Frequency Oscillation and Intrapulmonary Percussive Ventilation) do not maintain either constant peak pressure or tidal volume by any feedback mechanism. However, in both these cases there is open loop control of pressure with the operator making the adjustments. Hence we can still classify them as pressure control modes, it's just that the "control" is very crude.

\section{CPAP}

Continuous (ie, constant, unchanging) positive airway pressure; the set or measured mean value of transrespiratory system pressure during unassisted breathing or between assisted breaths. While this term is sometimes used synonymously for PEEP, historically, PEEP came first. PEEP mechanisms originally required the patient to drop transrespiratory system pressure to below atmospheric pressure to inhale, imposing a load and causing an increased work of breathing. CPAP mechanisms were developed so that the patient only had to drop pressure below the set CPAP level to inhale, thus decreasing the imposed load. See PEEP.

\author{
CSV \\ See CONTINUOUS SPONTANEOUS VENTILATION, \\ SPONTANEOUS BREATH
}

\section{CYCLE}

To end the inspiratory time (and begin expiratory flow)

\section{CYCLE VARIABLE}

The variable (usually pressure, volume, flow, or time) that is used to end inspiratory time (and begin expiratory flow).

\section{DRIVING PRESSURE}

Driving pressure (also called tidal pressure) is most often defined as tidal volume divided by compliance, equivalent to plateau pressure minus PEEP. Newton's 3rd law of motion says that for every action, there is an equal and opposite reaction.

Driving pressure can be understood within this framework as existing in two aspects (depending on the frame of reference) according to the equation of motion for the respiratory system: During mechanical ventilation, from the point of view of the lungs and chest wall, there is the experience of an active driving force attempting to inflate the lungs.

Total driving pressure has two components, dynamic and static. Dynamic driving pressure is the inflating force (generated by the ventilator) that is required to drive flow through the airways. During inflation with preset flow, dynamic driving pressure is measured as airway pressure above end expiratory pressure (usually PEEP) at any moment in the inspiratory time. Static driving pressure is the force required to maintain the inflation volume when flow is zero throughout the system and is measured as plateau pressure minus total PEEP (ie, from end inspiratory pause minus end expiratory pause pressures). From the point of view of the ventilator, there is a reactive force opposing inflation (the right hand side of the equation of motion). The dynamic component of this force is calculated as resistance times flow (resistive load). The static component is calculated as elastance times volume (elastic load) plus autoPEEP. See EQUATION OF MOTION

\section{DUAL TARGETING SCHEME}

A control system that allows the ventilator to switch between volume control and pressure control during a single inspiration. Dual targeting is a more advanced version of set- 
point targeting. It gives the ventilator the decision of whether the breath will be volume or pressure controlled according to the operator set priorities. The breath may start out in pressure control and automatically switch to volume control, as in the Bird "VAPS" mode or, the reverse, as in the Dräger "Pressure Limited" mode feature. The Maquet Servo-i ventilator has a mode called "Volume Control" and the operator presets both inspiratory time and tidal volume as would be expected with any conventional volume control mode. However, if the patient makes an inspiratory effort that decreases inspiratory pressure by $3 \mathrm{~cm} \mathrm{H} 2 \mathrm{O}$, the ventilator switches to pressure control and, if the effort lasts long enough, flow cycles the breath. Indeed, if the tidal volume and inspiratory time are set relatively low and the inspiratory effort is relatively large, the resultant breath delivery is indistinguishable from Pressure Support. As a result, the tidal volume may be much larger than the expected, preset value.

This highlights the need to understand dual targeting. Because both pressure and volume are the control variables during dual targeting, we identify the control variable as the one with which the breath initiates. This is because the alternate control variable may never be implemented during the breath, depending on the other factors in the targeting scheme.

\section{DUTY CYCLE}

The ratio of inspiratory time to total cycle time, usually expressed as a percent.

\section{DYNAMIC CHARACTERISTIC}

A term coined to describe a metric calculated as tidal volume divided by (peak inspiratory pressure minus plateau pressure) for a volume controlled breath with constant flow. This metric is often confused with dynamic compliance. Dynamic characteristic is always less than dynamic compliance due to the resistive pressure drop it contains (ie, peak inspiratory pressure has components due to both compliance and resistance). See STATIC COMPLIANCE, DYNAMIC COMPLIANCE. EQUATION OF MOTION.

\section{DYNAMIC COMPLIANCE}

The slope of the pressure-volume curve drawn between two points of zero flow (eg, at the start and end of inspiration). Dynamic compliance is less than static compliance for a system comprised of different time constants because some of the pressure is due to pendelluft between lung units. See STATIC COMPLIANCE, DYNAMIC CHARACTERISTIC

\section{DYNAMIC HYPERINFLATION}

The increase in lung volume that occurs whenever insufficient exhalation time prevents the respiratory system from returning to its normal resting end-expiratory equilibrium volume between breath cycles; the increase in lung volume associated with autoPEEP. Inappropriate operator set expiratory time may lead to dynamic hyperinflation, inability of the patient to trigger breaths, and an increased work of breathing.

\section{DYSSYNCHRONY}

Dyssynchrony during mechanical ventilation is defined as a no-zero phase difference between the pressure waveform representing patient inspiratory effort, Pmus, and the pressure waveform generated by the ventilator during an assisted breath.

See SYNCHRONY, ASYNCHRONY

\section{ELASTANCE}

Defined as the ratio of the change in the pressure difference across the system to the associated change in volume. A mechanical property of a structure such as the respiratory system; a parameter of a lung model, or setting of a lung simulator. Elastance is the reciprocal of compliance.

\section{ELASTIC LOAD}

The pressure difference applied across a system (e.g., a container) that sustains the system's volume relative to some reference volume, and/or the amount of its compressible contents relative to some reference amount. For a linear system: elastance ' volume, or, volume/compliance; for a container, the overall effective elastance (compliance) includes the elastances (compliances) of its structural components and the compressibility of the fluid (gas or liquid) within it.

\section{EQUATION OF MOTION FOR THE RESPIRATORY SYSTEM}

A mathematical relation among pressure difference, volume, and flow (as variable functions of time) that describes the physical interaction between the ventilator and the respiratory system. The simplest form is a differential equation with constant coefficients describing the respiratory system as a single deformable compartment including the lungs and chest wall connected in series to a single flow conducting tube. 


\author{
$\mathrm{P}(\mathrm{t})=$ Elastance $\mathrm{x}$ Volume $(\mathrm{t})+$ Resistance $\mathrm{x}$ Flow $(\mathrm{t})+$ \\ totalPEEP
}

In this equation, $\mathrm{P}$ is pressure difference across the system (eg, transrespiratory pressure or transpulmonary pressure). Pressure difference, volume, and flow are all functions of time (t). The left hand side may be expanded to distinguish pressure generated by the ventilator $\left(\mathrm{P}_{\text {vent }}\right)$ from the pressure generated by the inspiratory muscles $\left(\mathrm{P}_{\mathrm{mus}}\right)$.

$$
\begin{aligned}
& \mathrm{P}_{\text {vent }}(\mathrm{t})+\mathrm{P}_{\text {mus }}(\mathrm{t})=\text { Elastance } x \text { Volume }(\mathrm{t}) \\
& \text { Flow }(\mathrm{t})
\end{aligned}
$$

See ELASTIC LOAD, RESISTIVE LOAD

\section{EXPIRATORY FLOW}

The flow out of the airway opening during the expiratory time. By convention, expiratory flow is in the negative direction (below zero) in graphs.

\section{EXPIRATORY FLOW TIME}

The period from the start of expiratory flow to the instant when expiratory flow stops, usually expressed in seconds. Expired tidal volume is the integral of flow over the expiratory flow time.

\section{EXPIRATORY PAUSE TIME}

The period from cessation of expiratory flow to the start of inspiratory flow.

\section{EXPIRATORY PRESSURE}

General term for the pressure at the patient connection during the expiratory phase of mechanical ventilation. See EXPIRATORY PRESSURE TARGET

\section{EXPIRATORY PRESSURE TARGET}

Setting for maximum expiratory pressure during mechanical ventilation; also called PEEP. See EXPIRATORY PRESSURE, PEEP

\section{EXPIRATORY TIME}

Physiologically, this is the period from the start of expiratory flow to the start of inspiratory flow, usually expressed in seconds. Expiratory time equals expiratory flow time plus expiratory pause time. Expiratory time may also refer to a setting on a ventilator. For an actively breathing patient, these two definitions may not agree because the patient may superimpose a short spontaneous breath on top of a longer preset expiratory time.

\section{FEEDBACK CONTROL}

Closed loop control is accomplished by using the output as a signal that is fed back (compared) to the operator-set input such that the difference between the two is used to drive the system toward the desired output (ie, negative feedback control). For example, pressure control modes use airway pressure as the feedback signal to manipulate gas flow from the ventilator to maintain an inspiratory pressure set-point.

\section{$\mathrm{FIO}_{2}$}

Fraction of inspired oxygen; concentration of oxygen (usually expressed as a decimal value but also in percent) in a mixture of inspired gas.

\section{FLOW TRIGGERING}

The starting of inspiratory flow due to a patient inspiratory effort that generates inspiratory flow above a preset threshold. Flow triggering is a form of patient triggering.

\section{See SENSITIVITY}

\section{FLOW TARGET}

A preset value for inspiratory flow, usually specified as a peak flow and perhaps also as a particular waveform. See TARGET

\section{FLOW CYCLING}

The ending of inspiratory time due to inspiratory flow decay below a preset threshold. Flow cycling is a form of patient cycling.

\section{FULL VENTILATORY SUPPORT}

The ventilator provides all of the work of breathing; muscle pressure in the equation of motion is zero; achievable only with sedation and paralysis of patient. See PARTIAL VENTILATORY SUPPORT 
IMV

\section{See INTERMITTENT MANDATORY VENTILATION}

$\mathbf{I}: \mathbf{E}$

The ratio of inspiratory time to expiratory time.

For example, an I:E ratio of $1: 2$ is equivalent to $1 / 2$ or 0.5 . Hence an I:E ratio of 1:2 (0.5) is larger than a ratio of $1: 4$ $(0.25)$.

\section{INFLATION PRESSURE}

Airway pressure as a function of time during the inspiratory flow time. See INSPIRATORY PRESSURE, INSPIRATORY PRESSURE TARGET

\section{INSPIRATORY FLOW}

The flow into the airway opening during the inspiratory time. By convention, inspiratory flow is in the positive direction (above zero) in graphs.

\section{INSPIRATORY FLOW TIME}

The period from the start of inspiratory flow (into the airway opening) to the cessation of inspiratory flow, usually expressed in seconds.

\section{INSPIRATORY HOLD (PAUSE)}

An intentional maneuver during mechanical ventilation whereby the airway opening is occluded for a short period (inspiratory hold time) after an assisted inspiration. This maneuver is used to assess static respiratory system mechanics and also to increase mean airway pressure during volume control ventilation in an attempt to improve gas exchange.

\section{INSPIRATORY HOLD (PAUSE) TIME}

The period from the cessation of inspiratory flow (into the airway opening) to the start of expiratory flow during mechanical ventilation, during an inspiratory hold, usually expressed in seconds.

\section{INSPIRATORY PRESSURE}

Airway pressure as a function of time during the inspiratory time. See INFLATION PRESSURE, INSPIRATORY PRESSURE TARGET

\section{INSPIRATORY PRESSURE TARGET}

Setting for maximum inspiratory pressure during pressure control ventilation. The inspiratory pressure target may set relative to PEEP or to atmospheric pressure. See INSPIRATORY PRESSURE, see illustration above

\section{INSPIRATORY PRESSURE TIME}

The period during a pressure control breath equivalent to inspiratory time minus the sum of pressure rise time and inspiratory hold time

\section{INSPIRATORY TIME}

The period from the start of inspiratory flow to the start of expiratory flow. Alternative definitions for inspiratory time can be created that are relative to either the patient or the ventilator. Patient, or neural inspiratory time is defined as the duration of the neural signal to the diaphragm causing it to contract (eg, using the EAdi signal from a catheter designed for Neurally Adjusted Ventilatory Assist). Neural inspiratory time can be modeled as the duration of a positive change in muscle pressure on a breathing simulator.

Ventilator inspiratory time is defined in two different ways based on ventilator settings: (1) in volume control modes, ventilator inspiratory time is the period from the start of inspiratory flow to the start of expiratory flow and equal to inspiratory flow time (tidal volume/flow) plus inspiratory pause time (if any), (2) in pressure control modes, ventilator inspiratory time for mandatory breaths is generally preset but for spontaneous breaths it is the period from the start of pressure rise above PEEP (ventilator trigger event) to point when inspiratory flow meets the cycle threshold (ventilator cycle event).

\section{INTELLIGENT TARGETING SCHEME}

A ventilator control system that uses artificial intelligence programs such as fuzzy logic, rule based expert systems, and artificial neural networks. Examples include the rule based system used by SmartCare (Dräger Evita XL ventilator) and IntelliVent-ASV (Hamilton S1 ventilator). 


\section{INTERMITTENT MANDATORY VENTILATION}

Breath sequence for which spontaneous breaths are permitted between mandatory breaths. If a synchronization window is used to coordinate flow with inspiratory effort, it is called synchronized IMV (SIMV). Four varieties of IMV are: (1) Mandatory breaths are always delivered at the set frequency; (2) Mandatory breaths are suppressed when the spontaneous breath rate is greater than the set mandatory breath rate; (3) Mandatory breaths are suppressed when the spontaneous minute ventilation is greater than the set/target mandatory minute ventilation. (4) Mandatory breaths are suppressed when dual targetting allows the cycle variable to change from volume or time to flow for patientn triggered breaths. In contrast to CMV, with IMV the mandatory breath frequency can never be higher than the set rate but it may be lower.

See MACHINE TRIGGERING, PATIENT TRIGGERING, SYNCHRONIZATION WINDOW, TRIGGER WINDOW, CONTINUOUS M ANDATORY VENTILATION

\section{LOAD}

The pressure resisting the force applied by the ventilator to assist inspiration. See ELASTIC LOAD, RESISTIVE LOAD

\section{LOADED BREATH}

A breath during which all or part of inspiratory (or expiratory) flow is generated by the patient doing work on the ventilator. In simple terms, if the airway pressure falls below end expiratory pressure during inspiration, the inspiration is loaded. If pressure rises above baseline on expiration, then expiration is loaded.

\section{MACHINCE CYCLING}

Ending inspiratory time independent of signals representing the patient determined components of the equation of motion (Pmus, elastance, or resistance). Common examples are cycling due to a preset tidal volume or inspiratory time. If a patient signal (indicating expiration) occurs during an inspiratory time synchronization window, inspiration stops and is defined as a machine cycled event that ends a mandatory breath. See MACHINE TRIGGERING, PATIENT TRIGGERING, SYNCHRONICATION WINDOW, TRIGGER WINDOW, CONTINUOUS MANDATORY VENTILATION, INTERMITTENT MANDATORY VENTILATION

\section{MACHINE TRIGGERING}

Starting inspiratory flow based on a signal (usually time) from the ventilator, independent of a patient trigger signal. Examples include triggering based on a preset frequency (which sets the ventilatory period), or based on a preset minimum minute ventilation (determined by tidal volume divided by the ventilatory period). If a signal from the patient (indicating an inspiratory effort) occurs within a synchronization window, the start of inspiration is defined as a machine trigger event that begins a mandatory breath. See MACHINE CYCLING, PATIENT TRIGGERING, SYNCHRONIZATION WINDOW, TRIGGER WINDOW, CONTINUOUS MANDATORY VENTILATION, INTERMITTENT MANDATORY VENTILATION

\section{MANDATORY BREATH}

During mechanical ventilation, a mandatory breath is one for which inspiration is started or stopped by the ventilator, independent of the patient; inspiration is machine triggered or machine cycled. A mandatory breath can occur during a spontaneous breath (eg, High Frequency Jet Ventilation). A mandatory breath is, by definition, assisted. See ASSISTED BREATH, SPONTANEOUS BREATH

\section{MANDATORY MINUTE VENTILATION}

A form of intermittent mandatory ventilation in which the ventilator monitors the exhaled minute ventilation as a target variable. If the exhaled minute ventilation falls below the operator set value, the ventilator will trigger mandatory breaths or increase the inspiratory pressure until the target is reached. This is considered type 3 IMV (see Intermittent Mandaroty Ventilation).

\section{MEAN AIRWAY PRESSURE}

The average airway pressure over time, usually one ventilatory period.

\section{MECHANICAL VENTILATOR}

An automatic machine designed to provide all or part of the work required in generating enough breaths to satisfy the body's respiratory needs. 


\section{MINUTE VENTILATION}

The product of alveolar volume (tidal volume minus dead space volume) times ventilatory frequency, usually expressed in $\mathrm{L} / \mathrm{min}$.

\section{MINUTE VENTILATION}

The product of tidal volume times ventilatory frequency, usually expressed in $\mathrm{L} / \mathrm{min}$.

\section{MODE VARIETY}

A variation of a mode that requires description beyond control variable, breath sequence, and targeting schemes. For example, NAVA and PAV are two varieties of PC-CSVs that differ in the specific ways they implement servo targeting

\section{MODE OF VENTILATION}

A predetermined pattern of interaction between a patient and a ventilator, specified as a particular combination of control variable, breath sequence, and targeting schemes for primary and secondary breaths.

\section{MUSCLE PRESSURE}

The aggregate forces developed by the respiratory muscles to produce breathing movements. Pmus is not measurable directly but is estimated as the equivalent transrespiratory pressure required to inflate the passive respiratory system to the same tidal volume. See Pmus, TRANSRESPIRATORY PRESSURE, EQUATION OF MOTION

\section{NEGATIVE PRESSURE VENTILATION}

A type of assisted breathing for which transrespiratory pressure difference is generated by keeping airway pressure equal to atmospheric pressure and making body surface pressure less than atmospheric pressure. Examples would be ventilation with an "iron lung" or "chest cuirass".

\section{NEURALLY ADJUSTED VENTILATORY ASSIST}

The name of a mode using a servo targeting scheme in which the controller sets airway pressure to be proportional to patient effort based on the voltage recorded from diaphragmatic activity from sensors embedded in an orogastric or nasogastric tube.

\section{OPTIMAL TARGETING SCHEME}

A ventilator control system that automatically adjusts the targets of the ventilatory pattern to either minimize or maximize some overall performance characteristic. This is an advanced form of adaptive targeting. One example is Adaptive Support Ventilation (Hamilton Medical G5 ventilator) in which the ventilator adjusts the mandatory tidal volume and frequency (for a passive patient) is such a way as to minimize the work rate of ventilation.

\section{PARTIAL VENTILATORY SUPPORT}

The ventilator and the respiratory muscles each provide some of the work of breathing; muscle pressure adds to ventilator pressure in the equation of motion. See FULL VENTILATORY SUPPORT, EQUATION OF MOTION

\section{PASSIVE VENTILATION}

Inspiratory muscles do not contribute to the generation of inspiratory flow. Passive ventilation is assisted by definition (ie, the ventilator does all of the work of breathing). See ASSISTED BREATH

\section{PATIENT CYCLING}

Ending inspiratory time based on signals representing the patient determined components of the equation of motion, (Pmus, elastance, or resistance). Common examples of cycling variables are peak inspiratory pressure and percent inspiratory flow. See MACHINE TRIGGERING, MACHINE CYCLING, PATIENT TRIGGERING, PATIENT CYCLING

\section{PATIENT TRIGGERING}

Starting inspiration based on a patient signal occurring in a trigger window, independent of a machine trigger signal. The signal is related to one of the patient determined components of the equation of motion (Pmus, elastance, or resistance). Common examples of patient trigger variables are airway pressure drop below baseline and inspiratory flow due to patient effort. See MACHINE TRIGGERING, MACHINE CYCLING, SYNCHRONICATION WINDOW, TRIGGER WINDOW, CONTINUOUS MANDATORY VENTILATION, INTERMITTENT MANDATORY VENTILATION 


\section{PAUSE PRESSURE}

Airway pressure during the inspiratory hold (pause) time. See INSPIRATORY HOLD

\section{PC-CMV}

Pressure controlled continuous mandatory ventilation.

\section{PC-IMV}

Pressure controlled intermittent mandatory ventilation.

\section{PC-CSV}

Pressure controlled continuous spontaneous ventilation.

\section{PEAK AIRWAY PRESSURE}

The maximum airway pressure measured during a mechanically assisted inspiration, measured relative to atmospheric pressure.

\section{PEAK INSPIRATORY PRESSURE}

The maximum pressure (relative to atmospheric pressure) during inspiration. See INSPIRATORY PRESSURE TARGET

\section{PEEP}

Positive end expiratory pressure; the value of transrespiratory system pressure at end expiration. See CPAP, EXPIRATORY PRESSURE TARGET

\section{PLATEAU PRESSURE}

The pressure at the airway opening (relative to atmospheric pressure) during an inspiratory hold (ie, flow throughout the respiratory system is zero), ie, passive recoil pressure of the elastance of the respiratory system

\section{$\mathbf{P}_{\text {mus }}$}

Muscle pressure. The aggregate forces developed by the respiratory muscles to produce breathing movements. $P_{\text {mus }}$ is not measurable directly but is estimated as the equivalent transrespiratory pressure required to inflate the passive respiratory system to the same tidal volume. See

\section{TRANSRESPIRATORY PRESSURE, EQUATION OF MOTION}

\section{POSIVITVE PRESSURE VENTILATION}

A type of assisted breathing for which transrespiratory pressure difference is generated by raising airway pressure above body surface pressure (usually equal to atmospheric pressure). Examples would be ventilation with intensive care or transport ventilators.

\section{POWER}

The rate of work or work per unit of time. Power is calculated as work per breath times breath frequency (units are joules/minute)

\section{PRESSURE}

A measure of force per unit of area at a particular point in space.

\section{PRESSURE CHANGE}

The difference between pressure (or pressure gradient) measured at one point in time and the same pressure measured at a previous point in time.

\section{PRESSURE CONTROL}

A general category of ventilator modes for which pressure delivery is either proportional to patient effort or has a particular waveform regardless of respiratory system mechanics. When peak inspiratory pressure is preset, we further specify that inspiration must start out with the preset pressure to avoid confusion with dual targeting that may switch from a preset flow to a preset pressure (eg, Pmax feature used with volume control modes on the Dräger Evita Infinity V500 ventilator). See dual targeting scheme. According to the equation of motion, pressure control means that inspiratory pressure is predetermined as the independent variable so that volume and flow become the dependent variables. See VOLUME CONTROL, EQUATION OF MOTION, DUAL TARGETING

\section{PRESSURE GRADIENT}

The difference between pressure measured at one point in space and another point in space. Examples include the 
pressure difference across a cell membrane causing gas diffusion into the cell and the pressure difference across the respiratory system causing flow into the lungs. See

TRANSAIRWAY PRESSURE, TRANSALVEOLAR

PRESSURE, TRANSCHESTWALL PRESSURE, TRANSPULMONARY PRESSURE, TRANSRESPIRATORY PRESSURE

\section{PRESSURE CYCLING}

Ending inspiratory time when airway pressure reaches a preset threshold.

\section{PRESSURE RISE TIME}

see RISE TIME

\section{PRESSURE SUPPORT}

The name of a mode that is classified as pressure control continuous spontaneous ventilation with set-point targeting; inspiration is pressure or flow triggered and flow cycled.

\section{PRESSURE TRIGGERING}

The starting of inspiratory flow due to a patient inspiratory effort that generates an airway pressure drop below end expiratory pressure larger than a preset threshold (ie, the trigger sensitivity setting). Pressure triggering is a form of patient triggering.

\section{PRESSURE TARGET}

Ventilator setting indication that inspiratory pressure reaches a preset value before inspiration cycles off.

\section{PRIMARY BREATHS}

Mandatory breaths during CMV or IMV or spontaneous breaths during CSV.

\section{PROPORTIONAL ASSIST VENTILATION (PAV)}

The name of a mode that is classified as pressure control continuous spontaneous ventilation with servo targeting based on the equation of motion for the respiratory system and making inspiratory pressure proportional to inspiratory effort. See EQUATION OF MOTION
$\mathbf{P}_{\text {vent }}$

Total driving pressure during mechanical ventilation; elastance $\mathrm{x}$ volume + resistance $\mathrm{x}$ flow. See DRIVING PRESSURE, EQUATION OF MOTION

\section{RAMP}

A mathematical function whose value rises or falls at a constant rate. Ascending (rising) or descending (falling) functions are sometimes used for inspiratory flow in volume control modes.

\section{RESISTANCE}

The change in the pressure difference across the system to the associated change in flow. A mechanical property of a structure such as the respiratory system; a parameter of a lung model, or setting of a lung simulator

\section{RESISTIVE LOAD}

The pressure difference applied across a system (e.g., a container) that is related to a rate of change of the system's volume and/or the flow of fluid within or through the system. For a linear system: resistance $\mathrm{x}$ flow, or, resistance $\mathrm{x}$ rate of change of volume; for a container, the effective resistance includes the mechanical (usually viscous) resistances of its structural components and the flow resistance of the fluid [gas or liquid] within it.

\section{RISE TIME}

The period from the start of increase of a waveform above baseline to (or near) its peak value. To avoid ambiguity caused by noise in the signal, rise times are often specified as the period from $10 \%$ to $90 \%$ of peak value.

\section{SECONDARY BREATHS}

Spontaneous breaths during intermittent mandatory ventilation

\section{SENSITIVITY}

The sensitivity setting of the ventilator is the amount the trigger variable must change to start inspiratory flow. Sensitivity is sometimes used to refer to cycling also. The trigger or cycle threshold is the particular value of the trigger 
or cycle variable that initiates the event. For example, if a pressure trigger sensitivity is set at $-2 \mathrm{~cm} \mathrm{H} 2 \mathrm{O}$ below PEEP, and PEEP is set at $5 \mathrm{~cm} \mathrm{H} 2 \mathrm{O}$, then the trigger threshold is +3 cm H2O.

\section{SERVO TARGETING}

A control system for which the output of the ventilator automatically follows a varying input. In practice, this usually means that inspiratory pressure is proportional to inspiratory effort. For example, the Automatic Tube Compensation feature on the Dräger Evita 4 ventilator tracks flow and forces pressure to be equal to flow squared and multiplied by a constant (representing endotracheal tube resistance). Other examples include Proportional Assist Ventilation (Covidien PB 840 ventilator; pressure is proportional to spontaneous volume and flow) and Neurally Adjusted Ventilatory Assist (Maquet Servo-i ventilator; pressure is proportional to diaphragmatic electrical activity). For all three of these example modes airway pressure is effectively proportional to the patient's inspiratory effort.

\section{SET-POINT TARGETING}

A control system for which the operator sets the parameters of the pressure waveform (eg, inspiratory pressure, pressure rise time, and inspiratory time for pressure control modes) or volume and flow waveforms (eg, tidal volume and inspiratory flow for volume control modes). There are no targets set automatically by the ventilator. Advanced volume control modes actually allow the ventilator to make small adjustments to the set inspiratory flow to compensate for such factors as patient circuit compliance. From an engineering point of view, this is adaptive feedback control, but from a ventilator mode taxonomy point of view, such adjustments are better seen as a way of implementing operator preset values, and thus classified as set-point targeting.

\section{SINUSOIDAL}

A mathematical function having a magnitude that varies as the sine of an independent variable (eg, time). A sinusoidal function is sometimes used for inspiratory flow in volume control modes.

\section{SPECIFIC COMPLIANCE}

Compliance normalize to lung volume so that lung mechanics can be compared across different body sizes. Calculated as compliance divided by functional residual volume, FRC. See COMPLIANCE

\section{SPECIFIC ELASTANCE}

The inverse of specific compliance, ie, FRC divided by compliance.

See ELASTANCE, SPECIFIC COMPLIANCE

\section{SPONTANEOUS BREATH}

A breath for which both the start and end of inspiration are determined by the patient, independent of any machine settings for inspiratory time and expiratory time: inspiration is both patient triggered and patient cycled. As a result, the patient retains substantial control over timing. Note that use of this definition for determining the breath sequence (ie, CMV, IMV, CSV) assumes normal ventilator operation. For example, coughing during $\mathrm{VC}-\mathrm{CMV}$ may result in patient cycling for a patient triggered breath due to the pressure alarm limit. While inspiration for that breath is both patient triggered and patient cycled, this is not normal operation and the sequence does not turn into IMV. A spontaneous breath may occur during a mandatory breath (eg Airway Pressure Release Ventilation).A spontaneous breath may be assisted or unassisted. See ASSISTED BREATH, MANDATORY BREATH

$\mathrm{SPO}_{2}$

Transcutaneous blood oxygen saturation (in percent) obtained with a pulse oximeter.

\section{STATIC COMPLIANCE}

The slope of the pressure-volume curve drawn between two points of zero flow throughout the system (eg, at the start of inspiration and end of inspiratory hold). See DYNAMIC COMPLIANC, DYNAMIC CHARACTERISTIC.

\section{STRAIN}

The deformation of a structure associated with an applied stress. In terms of pulmonry physiology, strain is the lung volume change (ie, tidal volume) associated with the stress (change in transalveolar pressure) relative to the normal end expiratory lung volume (ie, functional residual capacity, FRC).

\section{STRESS}

The internal distribution of the counterforce per unit of area that balances and reacts to an external load. In terms of 
pulmonary physiology, stress is the tidal pressure associated with the delivery of a tidal volume. There is a linear relation between stress ( the change in transalveolar pressure, $\mathrm{P}_{\mathrm{TA}}$ or static transpulmonary pressure) and strain (the change in lung volume, V, above functional residual volume, FRC), with the constant of proportionality being specific lung elastance, $\mathrm{E}_{\mathrm{spec}}$ divided by FRC:

$$
\Delta \mathrm{P}_{\mathrm{TA}}=\mathrm{E}_{\text {spec }} \mathrm{x}(\Delta \mathrm{V} / \mathrm{FRC})
$$

Rearranging this equation yields

$$
\mathrm{E}_{\mathrm{spec}}=\Delta \mathrm{P}_{\mathrm{TA}} \times(\mathrm{FRC} / \Delta \mathrm{V})
$$

Now, if the change in $\Delta \mathrm{P}_{\mathrm{TA}}$ is large enough to make $\Delta \mathrm{V}$ equal to $\mathrm{FRC}$, then $\mathrm{FRC} / \Delta \mathrm{V}=1$ and specific elastance can be interpreted as the change in transalveolar pressure required to double the FRC.

\section{SYNCHRONIZED IMV (SIMV)}

A form of IMV in which mandatory breath delivery is coordinated with patient inspiratory effort. A synchronized breath is considered to be machine triggered. See INTERMITTENT MANDATORY VENTILATION

\section{SYNCHRONIZATION WINDOW}

A short period, at the end of a preset expiratory time or at the end of a preset inspiratory time (for pressure control inspirations) during which a patient signal may be used to synchronize a machine trigger or cycle event to a patient trigger signal. If the patient signal occurs during an expiratory time synchronization window, inspiration starts and is defined as a machine triggered event. This is because the mandatory breath would have been time triggered regardless of whether the patient signal had appeared or not and because the distinction is necessary to avoid logical inconsistencies in defining mandatory and spontaneous breaths which are the foundation of the mode taxonomy. If inspiration is triggered in a synchronization window, the actual ventilatory period for the previous breath will be shorter than the set ventilatory period (determined by the set mandatory breath frequency). Some ventilators add the lost time to the next mandatory breath period to maintain the set frequency. Sometimes a synchronization window is used at the end of the inspiratory time of a pressure controlled, time cycled breath (eg Airway Pressure Release Ventilation). If the patient signal occurs during such an inspiratory time synchronization window, expiration starts and is defined as a machine cycled event. See INTERMITTENT MANDATORY VENTILATION, MACHINE TRIGGERING, PATIENT TRIGGERING, TRIGGER WINDOW

\section{SYNCHRONY}

Synchrony during mechanical ventilation is defined as a zero phase difference between the pressure waveform representing patient inspiratory effort, Pmus, and the pressure waveform generated by the ventilator during an assisted breath.

\section{See DYSSYNCHRONY, ASYNCHRONY}

\section{TAG}

A mode classification, or taxonomic attribute grouping. A tag can be an acronym. For example the mode named Volume $\mathrm{A} / \mathrm{C}$ is classified as volume control (VC) continuous mandatory ventilation (CMV) with set-point targeting (s) and can be represented as VC-CMVs. Another example (using both primary and secondary breaths) would be PRVC SIMV classified as PC-IMVa,s, where the primary breath uses adaptive targeting (a) and the secondary breath uses set-point targeting (s). The mode named Adaptive Support Ventilation has multiple targeting for each type of breath (ie, both optimal, $\mathrm{o}$, and intelligent, i). It is classified as PC-IMVoi,oi.

\section{TARGET}

A predetermined goal of ventilator output. Targets can be viewed as the goals of the targeting scheme. Within-breath targets are the parameters of the pressure, volume, or flow waveform. Examples of within-breath targets include inspiratory flow or pressure and rise time (set-point targeting), tidal volume (dual targeting) and constant of proportionality between inspiratory pressure and patient effort (servo targeting). Note that preset values within a breath that end inspiration, such as tidal volume, inspiratory time, or percent of peak flow, are also cycle variables. Between-breath targets serve to modify the within-breath targets and/or the overall ventilatory pattern. Between-breath targets are used with more advanced targeting schemes, where targets act over multiple breaths. Examples of between-breath targets and targeting schemes include average tidal volume (for adaptive targeting), percent minute ventilation (for optimal targeting) and combined PCO2, volume, and frequency values describing a zone of comfort (for intelligent targeting). Symbols used for targeting schemes: $\mathrm{s}=$ set-point, $\mathrm{d}=$ dual, $\mathrm{b}=$ bio-variable, $\mathrm{r}=$ servo, $\mathrm{a}=$ adaptive, $\mathrm{o}=$ optimal, $\mathrm{i}=$ intelligent.

\section{TARGETING SCHEME}

A model of the relationship between operator inputs and ventilator outputs to achieve a specific ventilatory pattern, usually in the form of a feedback control system. The targeting scheme is a key component of a mode description. 


\section{TAXONOMY}

A hierarchical classification system. A taxonomy for modes of ventilation has four levels: 1) the control variable, 2) the breath sequence; 3 ) the targeting scheme for primary breaths and; 4) the targeting scheme for secondary breaths.

\section{TIDAL PRESSURE}

The change in transalveolar pressure associated with the inhalation or exhalation of a tidal volume. Calculated as tidal volume divided by compliance or plateau pressure minus total PEEP. Sometimes called driving pressure. See DRIVING PRESSURE

\section{TIDAL VOUME}

The volume of gas, either inhaled or exhaled, during a breath.

The maximum value of the volume vs time waveform, corresponding to the integral of flow from the start of inspiratory flow to the start of expiratory flow.

\section{TIME CONSTANT}

The time at which an exponential function attains $63 \%$ of its steady state value in response to a step input, calculated as the product of resistance and compliance (usually in units of seconds). The time necessary for inflated lungs to passively empty by $63 \%$; the time necessary for the lungs to passively fill $63 \%$ during pressure control ventilation with a rectangular pressure waveform. Passive inhalation or exhalation is virtually complete after 5 time constants.

\section{TIME CYCLING}

Ending inspiratory time after a preset time interval has elapsed. The most common examples are a preset inspiratory time or a preset inspiratory pause time. Time cycling is a form of machine cycling.

\section{TIME TRIGGERING}

The starting of inspiratory time due to a preset time interval. The most common example is a preset ventilatory frequency.

\section{TOTAL CYCLE TIME}

Same as ventilatory period, the sum of inspiratory time and expiratory time, usually expressed in seconds.

\section{TOTAL PEEP}

The sum of auto-PEEP and intentionally applied PEEP or CPAP.

\section{TOTAL VENTILATORY SUPPORT}

See FULL VENTILATORY SUPPORT

\section{TRANSAIRWAY PRESSURE}

Pressure at the airway opening minus pressure in the lungs (i.e., alveolar pressure).

\section{TRANSALVEOLAR PRESSURE}

Pressure in the lungs minus pressure in the pleural space. Equal to transpulmonary pressure only under static conditions.

\section{TRANSCHESTWALL PRESSURE}

Pressure in the pleural space minus pressure on the body surface.

\section{TRANSPULMONARY PRESSURE}

Pressure at the airway opening minus pressure in the pleural space.

\section{TRANSRESPIRATORY PRESSURE}

Pressure at the airway opening minus pressure on the body surface; equal to the sum of transairway pressure plus transalveolar pressure plus transchestwall pressure.

\section{TRANSTHORACIC PRESSURE}

Pressure in the lungs minus pressure on the body surface; equal to the sum of transalveolar pressure plus transchestwall pressure 


\section{TRIGGER}

To start the inspiratory time.

See MACHINE TRIGGERING, PATIENT TRIGGERING

\section{TRIGGER VARIABLE}

The variable (usually pressure, volume, flow, or time) that is used to start the inspiratory time.

\section{TRIGGER WINDOW}

The period comprised of the entire expiratory time minus a short "refractory" period at the end of the previous inspiration, required to reduce the risk of double triggering (eg, for CMV and CSV breath sequences) and minus any synchronization window (IMV breath sequences). If a signal from the patient (indicating an inspiratory effort) occurs within this trigger window, inspiration starts and is defined as a patient triggered event. See MACHINE TRIGGERING, MACHINE CYCLING, SYNCHRONICATION WINDOW, CONTINUOUS MANDATORY VENTILATION, INTERMITTENT MANDATORY VENTILATION

\section{VENTILATORY PATTERN}

A sequence of breaths (CMV, IMV, or CSV) with a designated control variable (volume or pressure) for the mandatory breaths (or the spontaneous breaths for CSV).

\section{VENTILATORY PERIOD}

The time from the start of inspiratory flow of one breath to the start of inspiratory flow of the next breath; inspiratory time plus expiratory time; the reciprocal of ventilatory frequency. Also called total cycle time or total breath cycle.

\section{VOLUME CONTROL}

A general category of ventilator modes for which both inspiratory flow and tidal volume are preset and independent of respiratory system mechanics. Usually, flow and tidal volume may be set directly by the operator. Alternatively, the ventilator may determine tidal volume based on operator preset values for frequency and minute ventilation or the ventilator may determine inspiratory flow based on operator set tidal volume and inspiratory time. When inspiratory volume and flow are preset, we further specify that inspiration must start out with the preset flow to avoid confusion with dual targeting that may switch from a preset pressure to a preset flow and volume (eg. Volume Assured Pressure Support). See dual targeting scheme. Note that setting tidal volume is a necessary but not sufficient criterion for volume control. The reason is that some ventilators use pressure control with adaptive targeting and allow the operator to set a tidal volume but not an inspiratory flow. In this case, the tidal volume setting refers to the between-breath tidal volume target, not a within-breath target. See adaptive targeting scheme. Likewise, setting inspiratory flow is also a necessary but not sufficient criterion for volume control. For example, the Bird Mark 7 ventilator requires an inspiratory flow setting but has no tidal volume setting. Instead the operator sets the inspiratory pressure, which is also the cycle variable. Hence, breaths are pressure controlled, and changing lung mechanics change the rate of pressure rise, the inspiratory time, and hence the delivered tidal volume as in other examples of pressure control. According to the equation of motion, volume control means that both volume and flow are predetermined as the independent variables and pressure is thus the dependent variable. See PRESSURE CONTROL, EQUATION OF MOTION

\section{VOLUME CYCLING}

Ending inspiratory time when inspiratory volume reaches a preset threshold (ie, tidal volume). Volume cycling is a form of machine cycling.

\section{VC-CMV}

Volume controlled continuous mandatory ventilation.

\section{VC-IMV}

Volume controlled intermittent mandatory ventilation.

\section{VOLUME TARGET}

A preset value for tidal volume that the ventilator is set to attain either within a breath or as an average over multiple breaths.

\section{VOLUME TRIGGERING}

The starting of inspiratory time due to a patient inspiratory effort that generates an inspiratory volume signal larger than a preset threshold (ie, the trigger sensitivity setting). 


\section{VOLUTRAUMA}

Ventilator induced lung injury caused by excessively large tidal volumes. See BAROTRAUMA

\section{WORK OF BREATHING}

The general definition of work is the integral of pressure change with respect to volume change during ventilation (units are joules per breath or joules per liter of tidal volume). Pressure means the pressure difference across a structure, eg, transrepsiratory pressure or transpulmonary pressure or the equivalent muscle pressure. There are two general components of work related to mechanical ventilation. One kind is the work performed by the ventilator on the patient, which is reflected by a positive change in airway pressure above baseline during inspiration. The second kind is the work the patient does on the ventilator to (eg, to trigger inspiration), which is reflected by a negative change in airway pressure

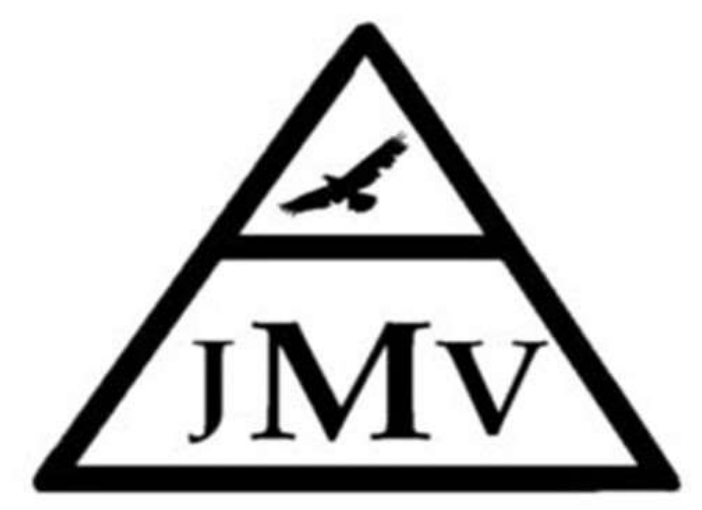

Journal of Mechanical Ventilation

\author{
Submit a manuscript
}

https://www.journalmechanicalventilation .com/submit-a-manuscript/ below baseline during inspiration. Different types of ventilator work include:

Total work: work generated by the ventilator to deliver pressure and flow to the respiratory system.

Resistive work: work dissipated as heat in generating flow through airway resistance

Elastic work: work needed to expand the lungs and chest wall

PEEP work: work against PEEP during inspiration which is temporarily stored as energy within the elastic tissues. It later converts to kinetic work as the gas escapes to atmosphere

Tidal work: elastic work minus PEEP work

Inspiratory work: the sum of tidal work and resistive work

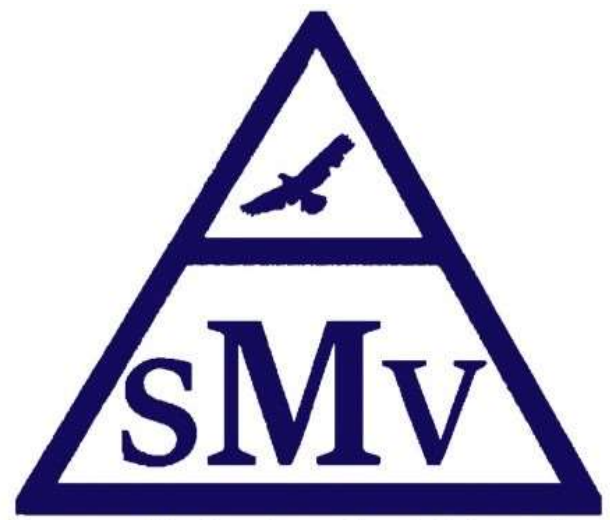

Society of Mechanical Ventilation

\author{
Free membership
}

https://societymechanicalventilation.org /membership/ 